\title{
Insulin signalling in skeletal muscle of subjects with or without Type II-diabetes and first degree relatives of patients with the disease
}

\author{
M. M. Meyer ${ }^{1}$, K. Levin ${ }^{2}$, T. Grimmsmann ${ }^{1}$, H. Beck-Nielsen ${ }^{2}$, H. H. Klein ${ }^{1}$ \\ ${ }^{1}$ Department of Internal Medicine, Medical University Lübeck, Lübeck, Germany \\ ${ }^{2}$ Diabetes Research Center, Odense University Hospital, Odense, Denmark
}

\begin{abstract}
Aims/hypothesis. Alterations in insulin signalling could contribute to insulin resistance in Type II (non-insulindependent) diabetes mellitus. Some of these alterations could be secondary to the diabetic state, ie. the hyperglycaemia or increased NEFA concentrations. We sought to exclude such secondary factors and to investigate whether Type II diabetes in itself is associated with altered insulin signalling in skeletal muscle.

Methods. Hyperinsulinaemic-euglycaemic clamps were performed in 10 obese Type II diabetic patients whose glucose concentrations had been normalised for $8 \mathrm{~h}$ by plasma glucose-adapted insulin infusion, $10 \mathrm{BMI}-$ matched first-degree relatives of Type II diabetic patients, and 10 BMI-matched non-diabetic subjects. Muscle biopsies were obtained before and at the end of the clamps, and insulin receptor kinase activity, phosphatidylinositol-3'-kinase activity, Akt-Thr ${ }^{308}$-phosphorylation, and glycogen synthase activity determined. Results. At similar steady-state clamp insulin concentrations $(\sim 400 \mathrm{pmol} / \mathrm{l})$ similar receptor kinase activities, phosphatidylinositol-3'-kinase activities, Akt$\mathrm{Thr}^{308}$-phosphorylation, and glycogen synthase activi-
\end{abstract}

ties were found in all subject groups although glucose disposal was reduced in the diabetic subjects and relatives. Pre-clamp signalling levels were different between subject groups, most likely due to different preclamp insulin concentrations.

Conclusion/interpretation. Our results in subjects at risk for the development of diabetes and Type II diabetic patients with normalized glucose concentrations suggest that Type II diabetes in itself is not associated with reduced signalling intensity at the studied signalling molecules, at least not at the chosen clamp insulin concentration and under the chosen conditions. Alterations responsible for the reduced glucose disposal could be located downstream of the investigated steps or in alternative insulin signalling pathways. A different spatial organisation of the investigated signalling molecules can also not be excluded. [Diabetologia (2002) 45:813-822]

Keywords Insulin signalling, human skeletal muscle, Type II diabetes, first-degree relatives, euglycaemichyperinsulinaemic clamp, insulin receptor kinase activity, PI3'-kinase activity, Akt, glycogen synthase activity.
Received: 31 October 2001 / Revised: 21 January 2002

Published online: 8 May 2002

C) Springer-Verlag 2002

M.M. Meyer and K. Levin contributed equally to the work

Corresponding author: H. H. Klein, Medizinische Klinik 1, Medizinische Universität zu Lübeck, Ratzeburger Allee 160, Lübeck, Germany, e-mail: klein@medinf.mu-luebeck.de

Abbreviations: Akt, Protein kinase B; AU, arbitrary units; FDR, non-diabetic first-degree relatives of diabetic subjects; GDR, glucose disposal rate; PI3', phosphatidylinositol 3'; p85, p85 subunit of phosphatidylinositol-3'-kinase
Type II (non-insulin-dependent) diabetes mellitus is associated with a reduced insulin-stimulated glucose disposal in skeletal muscle and other tissues [1]. Because insulin resistance is also observed in non-diabetic first-degree relatives of diabetic subjects $[2,3,4$, 5], and because it seems to precede the development of frank diabetes [6], an inherited basis of at least a part of the diabetes-associated insulin resistance has been proposed [7]. On the other hand metabolic abnormalities in the diabetic state itself such as hyper- 
glycaemia or increased NEFA concentrations also contribute to the overall insulin resistance found in overt diabetes $[8,9,10]$.

The proposed inherited factors and secondary metabolic components of the resistance in Type II diabetes could be caused, at least in part, by alterations in the signal transduction between the insulin receptor and downstream targets that regulate glucose metabolism. Although there is a growing body of information about the proximal steps of insulin signalling, the more distal pathways involved in insulin-stimulated glucose disposal are still not clear. Insulin elicits its biological actions by binding to its receptor. This is followed by receptor autophosphorylation, an activation of the receptor kinase, and the phosphorylation of several intracellular substrates. These include insulin receptor substrates-1 to 4 , Gab 1, and shc [11]. In skeletal muscle, IRS-1 appears to be most important [12]. Binding of tyrosine-phosphorylated insulin receptor substrates to the $85 \mathrm{kDa}$ regulatory subunit of the lipid kinase phosphatidylinositol-3'(PI3')-kinase then results in an activation of this enzyme, which is necessary for the insulin-mediated stimulation of glucose uptake and glycogen synthase [13]. Signalling downstream of PI3'-kinase to glucose uptake and glycogen synthesis appears to be mediated, at least in part, by the serine/threonine kinase Akt [14] which is activated by phosphorylation at the $\mathrm{Thr}^{308}$ and $\mathrm{Ser}^{473}$ residues. In addition to this pathway through PI3'kinase, alternative insulin signalling pathways could exist $[15,16]$ and one of these might include the proto-oncoprotein $\mathrm{Cbl}$ [17].

Insulin signalling in skeletal muscle of Type II diabetic subjects has been investigated in few studies, and the results are partially conflicting. Activation of insulin receptor kinase has been found to be either normal $[12,18]$ or decreased $[19,20]$ compared to BMI-matched control groups. Insulin action on IRSassociated PI3'-kinase activity has been reported to be reduced in Type II diabetes $[12,21,22]$. In two of these studies the insulin concentrations at which the reductions were observed, were, however very high $[12,22]$. In another study [23] the reduced insulin effect in obese Type II diabetic patients compared to lean non-diabetic subjects appeared to be mainly due to their obesity because no difference was observed compared to obese non-diabetic subjects. Akt phosphorylation or activity has been found to be reduced in incubated muscle strips from Type II diabetic patients incubated in vitro [24], but in biopsies obtained at supraphysiological plasma insulin concentrations [22] no differences with control subjects was observed. In all these studies the diabetic patients were hyperglycaemic until the euglycaemic clamps were started. It can therefore not be excluded that alterations in insulin signalling were secondary to conditions associated with the diabetic state like hyperglycaemia or increased NEFA concentrations or both.
Thus it has been demonstrated in rat skeletal muscle that hyperglycaemia or an increased flux through the hexosamine pathway can influence insulin signalling on the level of PI3'-kinase or Akt [25, 26]. It has also been shown that increased NEFA concentrations decrease PI3'-kinase activity in human skeletal muscle [27].

One strategy to avoid the influence of secondary metabolic alterations is the study of normoglycaemic subjects with a strong family history of Type II diabetes. Only recently two such studies were published [4, 5]. Whereas one of these studies [4] suggests reduced signalling at the level of IRS-1 and PI3'-kinase in these subjects, the data of the other study [5] suggest that other defects of insulin signal transduction and/or downstream components of glucose metabolism could play a greater role in the development of skeletal muscle insulin resistance.

In our study, we employed two strategies to avoid the influence of secondary metabolic alterations. Thus insulin signalling and action in an obese control group was compared to two groups of subjects: one BMImatched group with Type II diabetes whose glucose concentrations had been normalized for at least $8 \mathrm{~h}$ by plasma glucose-adapted insulin infusion, and one BMI-matched group of first-degree relatives of Type II diabetic patients (FDR) with normal glucose tolerance. Euglycaemic hyperinsulinaemic glucose clamps were performed, and in skeletal muscle biopsies obtained at basal and clamp insulin concentrations the protein amounts, and/or insulin stimulated phosphorylation or activity of known insulin signalling intermediates were evaluated.

\section{Subjects and methods}

Subjects. Altogether 10 obese subjects with Type II diabetes, 10 BMI-matched first-degree relatives of Type II diabetic subjects (FDR), and 10 BMI-matched control subjects with no family history of diabetes were recruited. All were Caucasians and sedentary. None of the subjects suffered from diseases other than diabetes and hypertension as evaluated by clinical investigation and standard laboratory assessments. In the diabetic subjects, all antidiabetic medication (four with sulphonylureas, two with metformin, and four with diet alone) and lipid lowering drugs were discontinued 3 weeks before the study. Subjects were instructed not to change diet and amount of physical activity during the study and to avoid excessive physical exercise at least 3 days before metabolic investigations. The FDR had as a minimum one first-degree relative and one second-degree relative with Type II diabetes. In the FDR and control subjects, normal glucose tolerance was ensured by an oral glucose tolerance test. Before entry into the study, the purpose and risks of the experimental protocol were carefully explained to all of the volunteers and informed written consent was obtained. The protocol was approved by the local ethical Committee and was in accordance with the Helsinki II Declaration.

Euglycaemic hyperinsulinaemic clamps. The diabetic patients were admitted to the clinical research centre the evening before 
in order to induce euglycaemic steady state $(5.2 \mathrm{mmol} / \mathrm{l})$ by a variable infusion of insulin by an antecubital vein catheter. Blood samples for plasma glucose analyses were drawn from a catheter inserted into a dorsal wrist vein of the opposite arm. The relatives and control subjects were admitted to the centre at $0800 \mathrm{~h}$ at which time intravenous catheters were inserted. During the study, the subjects remained in a supine position with the hand designated for collection of blood samples placed and maintained in a heated box for arterialization of venous blood [28]. After a $30 \mathrm{~min}$ relaxation period, a surface adjusted priming dose of $3-{ }^{3} \mathrm{H}$-glucose was given $\left(518 \mathrm{kBq} \mathrm{m}^{-2}\right)$ (DuPont-New England Nuclear, Boston, Mass., USA), followed by a continuous infusion of $3-{ }^{3} \mathrm{H}$-glucose $\left(5.18 \mathrm{kBq} \cdot \mathrm{min}^{-1} \cdot \mathrm{m}^{-2}\right)$. After a $120 \mathrm{~min}$ tracer equilibration period, insulin (Actrapid, Novo Nordisk, Bagsvaerd, Denmark) was infused at a rate of $40 \mathrm{mU} \cdot \mathrm{min}^{-1} \cdot \mathrm{m}^{-2}$ for $180 \mathrm{~min}$ and euglycaemia maintained using a variable infusion of $18 \%$ glucose. In order to keep plasma specific activity constant at the basal level during the clamp, $3{ }^{3} \mathrm{H}-$ glucose was added to the glucose infusate (HOT-GINF) as previously described [29]. Steady-state periods were defined as the last $30 \mathrm{~min}$ before the start and the last $30 \mathrm{~min}$ before the end of the $40 \mathrm{mU} \cdot \mathrm{min}^{-1} \cdot \mathrm{m}^{-2}$ insulin infusion, respectively. Rates of total glucose appearance (Ra) and glucose disappearance (Rd) were calculated from the plasma concentration of tritiated glucose and plasma glucose using Steele's non-steady-state equations [30]. In these calculations, the distribution volume of glucose was taken as $200 \mathrm{ml} \cdot \mathrm{kg}^{-1}$ body weight and the pool fraction as 0.65 . Plasma insulin was analysed by a two-site, time-resolved immunofluorometric assay [31]; non-esterified fatty acids were measured by an enzymatic colorimetric method (Wako Chemicals, Neuss, Germany) as were triglycerides (Boehringer Mannheim, Mannheim, Germany).

Muscle biopsies. At the end of each steady state period (referred to as pre-clamp and clamp period, respectively) a percutaneous muscle biopsy was taken under local anaesthesia (2\% lidocaine without epinephrine) from M. vastus lateralis $20 \mathrm{~cm}$ above the knee using the Bergstrom method [32] with suction. The biopsies were immediately frozen and stored in liquid nitrogen. In a subset of subjects, biopsies were also obtained 20 or $60 \mathrm{~min}$ after the start of the $40 \mathrm{mU} \cdot \mathrm{min}^{-1} \cdot \mathrm{m}^{-2}$ insulin infusion. For subsequent measurements, the biopsies were homogenized in solubilisation buffer $(10 \mu \mathrm{l}$ per mg muscle; $8 \mathrm{mmol} / \mathrm{l}$ EDTA, $20 \mathrm{mmol} / \mathrm{l}$ Hepes, 1\% IGEPAL, $530 \mathrm{mmol} / \mathrm{l} \mathrm{NaF}$, $30 \mathrm{mmol} / \mathrm{l}$ sodium pyrophosphate, $7 \mathrm{mmol} / \mathrm{l}$ sodium vanadate, $2 \mathrm{mmol} / \mathrm{l}$ dichloroacetic acid, $9 \mathrm{mmol} / \mathrm{l} \mathrm{PMSF}, 21 \mathrm{mmol} / \mathrm{l}$ benzamidine, $5 \mu \mathrm{mol} / \mathrm{l}$ leupeptin, $4 \mu \mathrm{mol} / \mathrm{l}$ pepstatin, and $10 \mu \mathrm{g} / \mathrm{ml}$ aprotinin, $\mathrm{pH} 7.4$ ) at $4^{\circ} \mathrm{C}$. Detergent insoluble material was removed by centrifugation at $12000 \times \mathrm{g}$ for $20 \mathrm{~min}$ and protein concentration measured with the BioRad protein assay (BioRad, Munich, Germany).

Insulin receptor kinase and binding activities. Insulin receptor kinase and binding activities were measured essentially as described [33, 34]. Briefly, $40 \mu \mathrm{l}$ of solubilized muscle sample were added to microwells coated with anti-insulin receptor antibody for $16 \mathrm{~h}$ at $4{ }^{\circ} \mathrm{C}$. The wells were washed and receptor-mediated ${ }^{32} \mathrm{P}$-incorporation into recombinant IRS-1 measured at a ${ }^{32} \mathrm{P}$-ATP concentration of $120 \mathrm{nmol} / \mathrm{l}$ and $2.3 \mu \mathrm{g} / \mathrm{ml}$ recombinant IRS-1 (Upstate Biotechnology Incorporated, New York, USA). [125I-Tyr-A $\left.{ }^{14}\right]$-monoiodoinsulin (Amersham-Pharmacia, Freiburg, Germany) binding to immobilized insulin receptors was also measured in the wells as described [33]. Insulin binding capacity was defined as the amount of specifically bound insulin at a concentration of $8.7 \mathrm{nmol} / \mathrm{l}$ [18]. Insulin receptor kinase activity was ex- pressed as amol $\mathrm{P}$ incorporated into IRS-1 per min per fmol insulin binding capacity.

Immunoblots. For quantification of IRS-1, solubilized muscle (620 $\mu$ g protein) was immunoimmobilised with anti-IRS-1 antibody ( $2 \mu \mathrm{g}$; Upstate Biotechnology, New York, USA) coupled to protein G-agarose (ImmunoPure, Pierce, Rockford, Ill., USA). Proteins were detached in Laemmli sample buffer, subjected to SDS-Page, transferred to nitrocellulose membranes (Schleicher \& Schuell, Dassel, Germany) and immunoblotted with the same anti-IRS-1 antibody. For quantification of total p85 subunit of $\mathrm{PI} 3^{\prime}$-kinase, Akt, and $\mathrm{Thr}^{308}$ phosphorylated Akt, solubilized muscle $(25 \mu \mathrm{g}, 60 \mu \mathrm{g}$ or $150 \mu \mathrm{g}$ protein for p85, Akt or phosphorylation of Akt, respectively) was subjected to SDS-PAGE. Proteins were transferred to nitrocellulose membranes and detected with specific antibodies against p85 (Upstate Biotechnology), Akt or $\mathrm{Thr}^{308}$-phosphorylated Akt (both BioLabs, Beverly, N. Engl., USA), horseradish peroxidase-labelled second antibodies (Dako Diagnostics, Hamburg, Germany), and enhanced chemiluminiscence (ECL; AmershamPharmacia, Freiburg, Germany). Bands were quantified densitometrically.

PI3'-kinase activity. Solubilized muscle (260 $\mu \mathrm{g}$ protein) was added to microwells that had been coated with $\alpha$-IRS-1 [35] (Upstate Biotechnology) as previously described [36]. After $16 \mathrm{~h}$ at $4^{\circ} \mathrm{C}$, the wells were washed and $30 \mu \mathrm{l}$ of a mixture of phosphatidylinositol (10 $\mu \mathrm{g} / \mathrm{sample}$; Sigma, Deisenhofen, Germany), $10 \mathrm{mmol} / \mathrm{l}$ Tris (pH 7.5), $100 \mathrm{mmol} / \mathrm{l} \mathrm{NaCl}, 1 \mathrm{mmol} / \mathrm{l}$ EDTA and $15 \mathrm{mmol} / \mathrm{l} \mathrm{MgCl}_{2}$ were added. The reaction was started by the addition of $5 \mu \mathrm{l}$ of a solution that contained 720 umol/l ${ }^{32} \mathrm{P}-\mathrm{ATP}$ (462.5 kBq/well; NEN, Dreieich, Germany). After $1 \mathrm{~h}$ at room temperature the reaction was stopped by the addition of $20 \mu \mathrm{l} 25 \% \mathrm{HCl}$ and $95 \mu \mathrm{l}$ of methanol/chloroform $(1: 1)$. The organic phase was extracted and applied to a silica gel thin layer chromatography plate. Phosphorylation was then determined using a PhosphorImager (PC Bas 100, Fuji, Tokyo, Japan). The microwell assay was carefully characterized. Thus control experiments revealed that all IRS- 1 in the skeletal muscle samples bound to the antibody, and that a doubling of the protein amount in the skeletal muscle sample also resulted in twice the signal intensity (data not shown). In the presence of wortmannin almost no signal was detectable.

Glycogen synthase activity. Extraction of muscle samples and assays for glycogen synthase were carried out as previously described [37, 38]. Briefly, glycogen synthase was assayed in the presence of a near physiological concentration of glucose6-phosphate (G6P; $0.1 \mathrm{mmol} / \mathrm{l})$ and in the presence of $10 \mathrm{mmol} / \mathrm{l}$ G6P to determine maximal enzyme activity. The substrate concentration of uridine diphosphate glucose was $0.31 \mathrm{mmol} / \mathrm{l}$ and glycogen synthase activity expressed as nmol of uridine diphosphate glucose incorporated into glycogen each minute for each milligram extract protein. Fractional velocities (FV) were calculated as the ratio between glycogen synthase activities assayed at 0.1 and $10 \mathrm{mmol} / \mathrm{l} \mathrm{G6P}$ (FV 0.1).

Experimental design and data analysis. To exclude distortion of the results due to interassay variation, always biopsies obtained at the basal and steady-state clamp insulin concentrations of one control subject, one FDR and one diabetic subject were analysed in parallel in one experiment. Where appropriate, arbitrary units (AU) were calculated. This was done by dividing the densitometric (Western blots) or phosphorimagerderived value (PI3'-kinase activity) obtained for the individual sample by the average value of all six samples (basal and clamp biopsies from one control, one FDR, and one diabetic 
subject) studied in parallel within the same experiment. Statistical analysis of paired data was performed by the Student's $t$ test. Statistical differences between groups were evaluated by ANOVA and the Student-Newman-Keul's post hoc test. Differences were considered to be statistically significant if $p$ was less than 0.05 .

\section{Results}

Metabolic characteristics of study subjects and insulin stimulation of glucose disposal. The data in Table 1 show that individuals in all three study groups were matched for BMI. Compared to the control group, glucose and NEFA concentrations were significantly higher in the diabetic subjects (Table 1), but were reduced to concentrations that were comparable to the control subjects and FDR by the overnight insulin infusion (Figs. $1 \mathrm{~A}$ and $\mathrm{B}$; data for the initial $8 \mathrm{~h}$ of the insulin infusion are not shown). The $40 \mathrm{mU} \cdot \mathrm{min}^{-1} \cdot \mathrm{m}^{-2}$ insulin infusion during the clamp reduced NEFA concentrations in all subject groups but was most effective in the control subjects. Compared to the control subjects, glucose disposal in the steady-state period of the clamp (defined as the last $30 \mathrm{~min}$ ) was significantly lower in the diabetic subjects and FDR (Fig. 1C).

Insulin signalling. Plasma insulin concentrations obtained at the end of the pre-clamp period were higher in the FDR $(71.1 \pm 12.1 \mathrm{pmol} / \mathrm{l})$ and diabetic $(182.2 \pm 23.5 \mathrm{pmol} / \mathrm{l})$ than in the control group $(37.5 \pm 2.5 \mathrm{pmol} / \mathrm{l})$. Steady-state plasma insulin concentrations were reached within $10 \mathrm{~min}$ (data not shown) after the start of the $40 \mathrm{mU} \cdot \mathrm{min}^{-1} \cdot \mathrm{m}^{-2}$ insulin infusion, and these were similar in all subject groups $(393.1 \pm 27.8 \mathrm{pmol} / \mathrm{l}, 398.3 \pm 20.7 \mathrm{pmol} / \mathrm{l}$ and $390.6 \pm 21.2 \mathrm{pmol} / 1$, respectively; Fig. $2 \mathrm{~A})$. In the control subjects, insulin receptor kinase activity was 6.2-fold, IRS-1-associated PI3'-kinase activity twofold, $\mathrm{Thr}^{308}$ phosphorylation of Akt 2.9-fold, and glycogen synthase activity 1.9-fold higher at the end of the clamp insulin infusion compared to pre-clamp levels (Fig. 2B-E). These increases were smaller in the diabetic subjects but because the values before
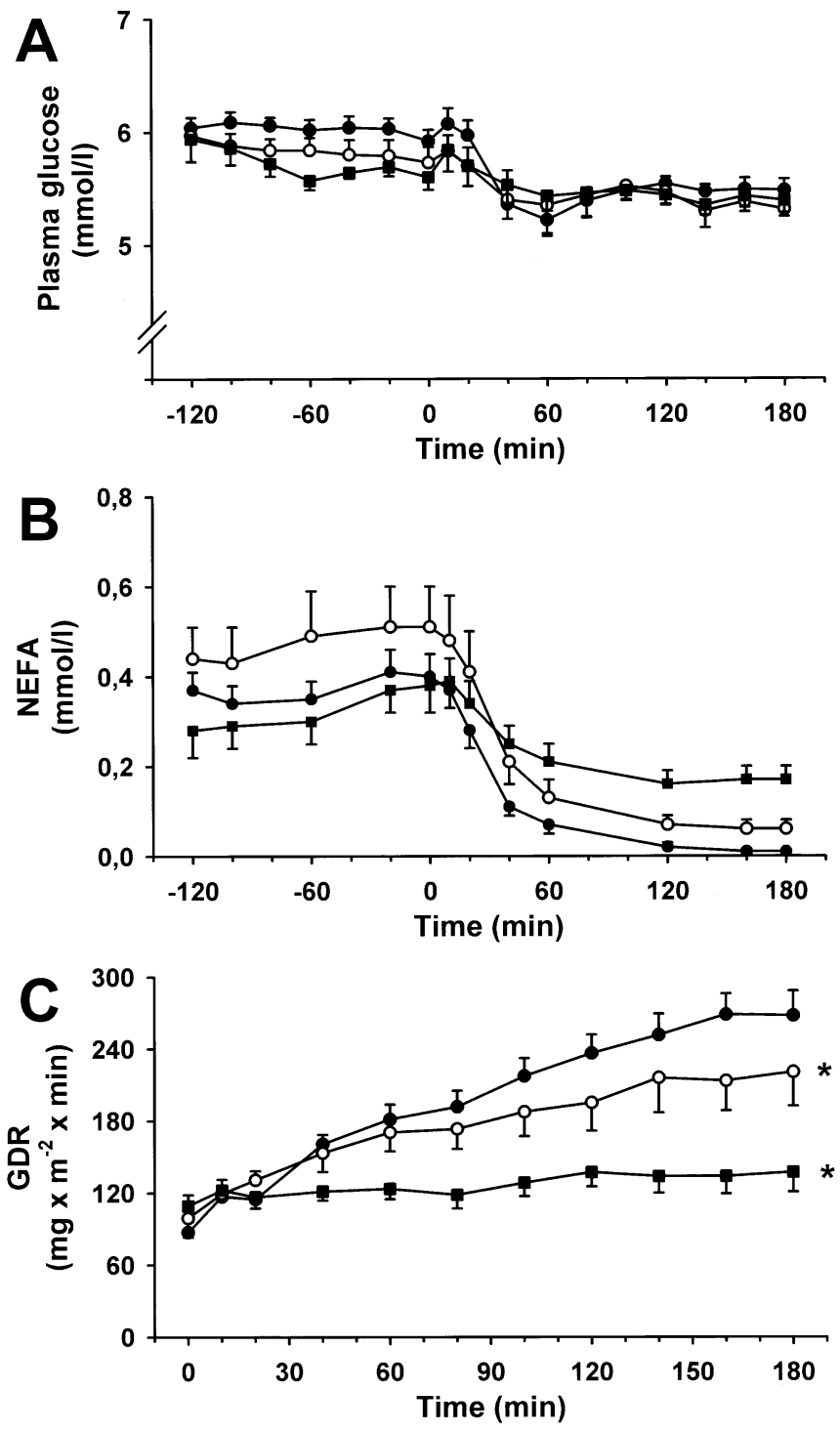

Fig. 1A-C. Plasma glucose concentrations (A), non-esterified fatty acid levels $(\mathbf{B})$, and glucose disposal rates $(\mathbf{C})$. Shown are the respective parameters $120 \mathrm{~min}$ before $(\mathbf{A}, \mathbf{B})$ and after the start of the $40 \mathrm{mU} \cdot \mathrm{min}^{-1} \cdot \mathrm{m}^{-2}$ insulin infusions $(\mathbf{A}, \mathbf{B}, \mathbf{C})$ for control subjects (O), first degree relatives $(\bigcirc)$, and diabetic subjects $(\boldsymbol{\square})$. In diabetic subjects, euglycaemia had been maintained overnight by variable insulin infusion as described in Methods. Shown are means $\pm \operatorname{SEM}(n=10 ; * p \leq 0.05$ compared to the control subjects during steady state period)

Table 1. Subject characteristics. Laboratory data were analysed in plasma of blood drawn under fasting conditions in the morning two days before the glucose clamp. Data are means \pm SEM

\begin{tabular}{lccc}
\hline & Control subjects & FDR & Type 2 diabetic subjects \\
\hline$n$ (male/female) & $10(10 / 0)$ & $10(7 / 3)$ & $10(8 / 2)$ \\
Age (years) & $57.9 \pm 2.3$ & $30.7 \pm 1.6^{\mathrm{a}}$ & $52.3 \pm 2.2^{\mathrm{b}}$ \\
BMI (kg/m $\left.{ }^{2}\right)$ & $29.8 \pm 0.8$ & $30.5 \pm 1.4$ & $31.8 \pm 1.2$ \\
Insulin (pmol/l) & $39.2 \pm 3.0$ & $72.1 \pm 12.5$ & $94.4 \pm 38.6$ \\
Glucose (mmol/l) & $5.5 \pm 0.14$ & $5.8 \pm 0.10$ & $12.6 \pm 1.4^{\mathrm{a}, \mathrm{b}}$ \\
NEFA (mmol/l) & $0.37 \pm 0.04$ & $0.44 \pm 0.07$ & $0.63 \pm 0.07 \mathrm{a}, \mathrm{b}$ \\
Triglycerides (mmol/l) & $1.3 \pm 0.23$ & $2.0 \pm 0.29$ & $3.3 \pm 1.32$ \\
\hline
\end{tabular}

${ }^{\text {a }} p \leq 0.05$ compared to control subjects

${ }^{\mathrm{b}} p \leq 0.05$ compared to FDR 

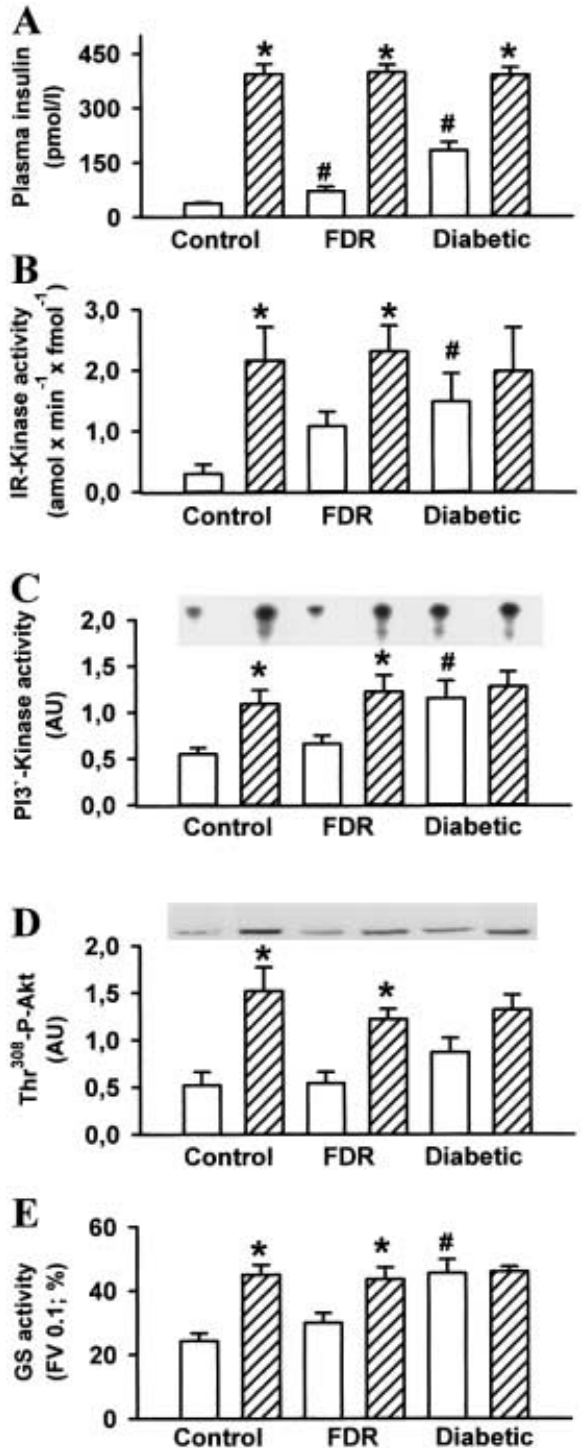

Fig. 2A-E. Plasma insulin concentration, insulin receptor (IR) kinase activity, IRS-1 associated PI3'-kinase activity, Akt $\mathrm{Thr}^{308}$-phosphorylation, and glycogen synthase (GS) activity at the end of the pre-clamp (open bars) and clamp periods (hatched bars). Muscle biopsies obtained immediately before the start (pre-clamp biopsies) or the end of the $40 \mathrm{mU} \cdot \mathrm{min}^{-1} \cdot \mathrm{m}^{-2}$ insulin infusions (clamp biopsies) were solubilized and insulin receptor kinase activity against recombinant IRS-1, IRS-1 associated PI3'-kinase activity, Thr $^{308}$-phosphorylation of Akt, and glycogen synthase activity determined as described. Shown are means \pm SEM $(n=7-10 ; * p \leq 0.05$ compared to pre-clamp biopsies; ${ }^{*} p \leq 0.05$ compared to control subjects)

the clamp insulin infusion were higher, absolute activities or phosphorylation states at the end of the clamp period were similar to the control group. In the FDR group, a tendency to higher pre-clamp signalling levels compared to the control subjects was observed for insulin receptor kinase activity, PI3'-kinase activity and glycogen synthase activity; this did, however, not reach statistical significance. As in the diabetic patients, absolute activities or phosphoryla-

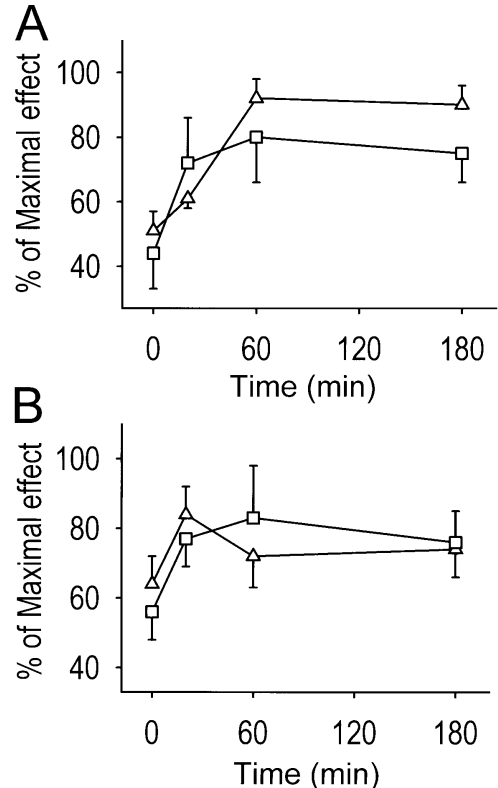

Fig. 3A, B. Time course for the activation of PI3'-kinase and Akt $\mathrm{Thr}^{308}$-phosphorylation in FDR (A) and diabetic subjects (B). In addition to the biopsies obtained immediately before (0 min) and at the 180th min after the start of the insulin infusion, biopsies were also obtained at the 20th min (in 6 out of 10 subjects) or the 60th min (in 4 out of 10 subjects) in the FDR and diabetic group. IRS-1-associated PI3'kinase activity $(\triangle)$ and Akt $\mathrm{Thr}^{308}$-phosphorylation $(\square)$ were determined as described. In individual subjects, the highest value measured at either time point $(0,20,180 \mathrm{~min}$, or $0,60,180 \mathrm{~min})$ was set to $100 \%$, and the values at the other time points expressed as percentage. Data represent means \pm SEM $(n=4-10)$

tion states at the end of the clamp period were similar to the control group. Thus at similar clamp insulin concentrations insulin receptor kinase activity, PI3'-kinase activity, $\mathrm{Thr}^{308}$-phosphorylation of Akt, and glycogen synthase activity were similar in all subject groups despite different glucose disposal rates (Fig. 1C).

To explore the time course of activation of IRS-1associated $\mathrm{PI} 3^{\prime}$-kinase and $\mathrm{Thr}^{308}$ phosphorylation of Akt in response to the insulin infusion, biopsies were also obtained at the 20th min after the start of the clamp insulin infusion in some subjects and at the 60 th min of the insulin infusion in other subjects (Fig. 3). These data suggest that constant signalling levels are reached before the 60th $\mathrm{min}$, and that no transient peaks with higher signal levels exist.

There were no detectable differences in insulin binding capacities or in the protein expression of the signalling molecules between the different subject groups (Table 2 ). This was also the case for the maximal glycogen synthase activities, suggesting that the protein expression of this enzyme was also similar (Table 2 ). 
Table 2 Insulin binding capacity (IBC), amounts of IRS-1, p85and Akt, and maximal glycogen synthase (GS) activity in preclamp and clamp biopsies. Data represent means \pm SEM, $n=8-10$

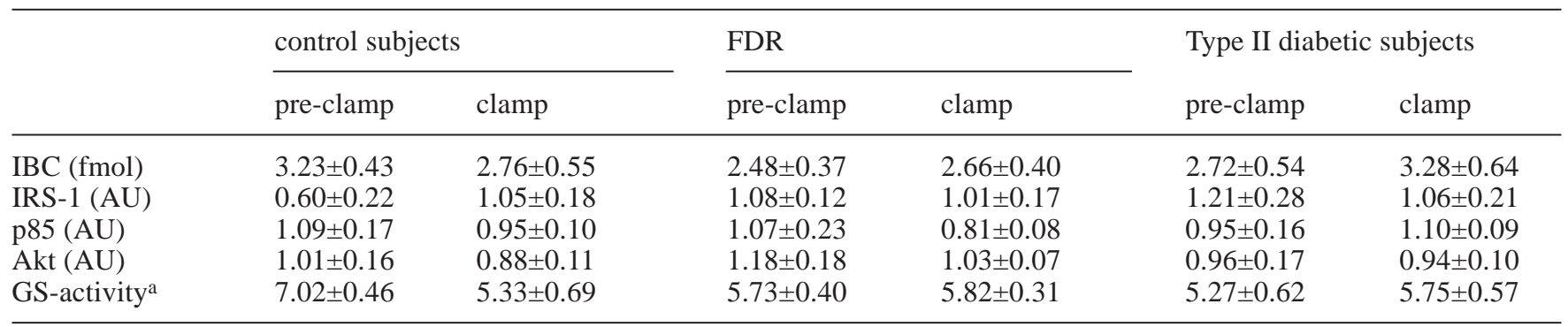

a Uridine diphosphate glucose incorporated in glycogen/mg protein/min in the presence of $10 \mathrm{mmol} / \mathrm{l} \mathrm{G6P}$

\section{Discussion}

An important observation in this study was that at similar steady-state clamp insulin concentrations (400 pmol/l) glucose disposal was lower in the diabetic patients and FDR, but no differences in insulin receptor kinase activity, PI3'-kinase activity, or Thr ${ }^{308}$ phosphorylation of Akt were found between subject groups. The data suggest that, at least under these conditions, the observed insulin resistance in the diabetic subjects and FDR was caused by alterations at nonstudied locations, eg. downstream signalling elements, alternative pathways [17, 39], or the final glucose transport effector system itself. It must also be considered that, in the intact cell, the compartmentalisation of the investigated signalling molecules may be very important. Thus we cannot exclude that despite similar overall activity/phosphorylation of the investigated signalling molecules an altered spatial organisation could contribute to an altered signalling in FDR and diabetic subjects.

We chose to obtain the insulin-stimulated biopsy at the $180^{\text {th }}$ min of the clamp insulin infusion [22] because at this time point a steady-state between arterial and interstitial insulin [40] and steady-state glucose disposal has been reached. Moreover, our present time-course data in the FDR and diabetic subjects and previous data by other authors [41, 42] and us [43] in non-diabetic subjects suggest that maximum levels of PI3'-kinase activity and Akt phosphorylation are reached within 20-60 min of insulin infusion, and thereafter remain fairly constant if the infusion is continued. Presumably, signalling at these steps had therefore been almost stable for about $90 \mathrm{~min}$ in our study before glucose disposal was determined in the steady state period (150th to 180th min). This makes it rather unlikely that the observed differences in glucose disposal between the study groups were caused by different signalling kinetics.

Compared to the control group, the insulin-stimulated increments of some of the signalling parameters tended to be slightly smaller in the FDR group, and were clearly smaller in the diabetic group. This was caused by the higher signalling levels in the pre-clamp biopsies rather than by differences in the biopsies obtained at the clamp insulin concentrations. It is likely that the increased pre-clamp insulin concentrations in these subject groups account completely, or almost completely, for the higher pre-clamp signalling concentrations, especially if one considers the logarithmic dependency between the insulin concentration and insulin signalling parameters that was described for human skeletal muscle [44] and isolated human skeletal muscle cells [36]. The smaller increments in insulin signalling therefore most likely do not reflect an impaired signalling. On the other hand, it can also not be excluded that sustainedly increased basal signalling levels lead to a desensitation of signalling steps downstream of PI3'-kinase or Akt, and thus contributed to the lower insulin-stimulated glucose disposal in the diabetic subjects and FDR. Thus, alterations of basal signalling levels could have indirectly contributed to the lower glucose disposal in the diabetic subjects and FDR. In any case, our data provide evidence that, at least at the chosen clamp insulin concentration and under the chosen conditions, the substantial diabetesassociated reduction in glucose disposal in these subject groups was not the direct consequence of reduced signalling at the investigated steps.

The finding that insulin receptor kinase activity in the biopsies obtained at the steady state clamp insulin concentration was similar in all subject groups is consistent with our previous report [18] where we also observed a similar activation of insulin receptor kinase in BMI-matched subjects with or without diabetes. In contrast to this previous study we used recombinant IRS-1 as substrate, which, in contrast to the previously used Glu4:Tyr1-polymer, associates with the insulin receptor through its phosphotyrosine binding (PTB)-domain [45]. Because potential alterations of this insulin receptor - IRS-1 interaction in diabetes could have been missed using the synthetic polymer, our data not only confirm but also extend our previous findings. Other investigators have previously described normal [12] or impaired [20, 46] insulin receptor phosphorylation or activation in diabetic subjects, and, most recently, no impairment of insulin receptor phosphorylation was shown in FDR of dia- 
betic subjects [4]. Potential reasons for the different findings by different groups include differences in methodologies and study cohorts and have been discussed extensively in our previous paper [18].

The question whether insulin-stimulated PI3'kinase activity or Akt phosphorylation is reduced in Type II-diabetic subjects or FDR has also been addressed previously. In two studies, PI3'-kinase activity at the clamp insulin concentration was found to be reduced in diabetic individuals [22] or FDR [4] compared to control subjects, whereas Akt phosphorylation was normal [22], or at least not statistically significantly impaired [4]. In several other studies, similar to our observation, IRS-1-associated PI3'-kinase activity and Akt phosphorylation at similar clamp insulin concentrations were not, or at least not statistically significantly, reduced in diabetic subjects [21, 23] or FDR [5], and only the insulin-stimulated increments of IRS-1-associated PI3'kinase-activity [5, 21] or Akt-phosphorylation [5] were smaller. As previously discussed for our data, that does not necessarily mean that signalling was impaired. Pre-clamp insulin concentrations in the diabetic subjects and FDR were higher than in the control subjects in these studies, and therefore could explain the increased pre-clamp signalling intensities.

One potential reason why diabetes-associated differences in certain insulin signalling parameters have been observed in some previous studies with diabetic subjects [21, 22], but not in another [23] and not in our present study could be the fact that in all but our study, diabetic subjects were severely hyperglycaemic until the euglycaemic glucose clamps were started. It is known that hyperglycaemia or an increased flux through the hexosamine pathway reduces insulin signalling at the level of PI3'-kinase or Akt in rat skeletal muscle $[25,26]$. In addition, NEFA concentrations are usually increased in the diabetic state, and increased NEFA concentrations have been shown to substantially reduce PI3'-kinase activity in human skeletal muscle [27]. Thus, it cannot be excluded that any alterations that have been observed in diabetic subjects in these studies [21,22] were secondary to conditions that were associated with their diabetic state rather than directly with the disease itself. Another reason for the observation of a decreased IRS-1-associated PI3'-kinase activity in the diabetic subjects in [22] but not in our study could be the about tenfold higher steady state clamp insulin concentrations in their study. Although this high insulin concentration is advantageous with respect to the signals that are produced, it is not clear whether the results reflect the situation at physiological insulin concentrations. It is, for example, possible that potential feed-back mechanisms, eg. the serine phosphorylation of IRS- 1 by GSK-3 [47], operate differently at such high insulin concentrations, or that transendothelial insulin transport is altered [48]. Finally, because at the high insulin concentration used by investigators [22], glucose disposal is maximally stimulated at least in control subjects [46, 49], consequences of an altered signalling for glucose disposal are not clear. The notion that a reduction in PI3'-kinase activity in diabetic subjects might occur at high, but not at physiological, insulin concentrations is also supported by a study with muscle strips from non-diabetic and diabetic subjects that were incubated in vitro [12], and where no difference in PI3'-kinase activity was detected below $2.4 \mathrm{nmol} / \mathrm{l}$ insulin.

The normalization of hyperglycaemia in the diabetic patients in our study required an infusion of insulin that contributed to the higher pre-clamp plasma insulin concentrations. It could be argued that this insulin-stimulation before the actual hyperinsulinaemic clamp procedure might in some way have influenced the signalling levels measured at the end of the steady-state hyperinsulinaemic period, and thus could have compensated potential signalling deficiencies that otherwise exist in diabetic patients. We cannot completely exclude such an unlikely scenario. However, even if this scenario were true, the discrepancy between normal signalling levels and reduced glucose disposal would remain and suggest impairments of insulin signalling at non-studied locations. We must also point out that plasma insulin concentrations in the diabetic patients would also have been higher if glucose concentrations had not been normalised by the insulin infusion (Table 1), and that in the previous studies pre-clamp plasma insulin concentrations were also higher in the hyperglycaemic diabetic patients $[21,22$, $23]$ and FDR $[4,5]$.

Moreover, our findings in the diabetic group are confirmed by our data in the FDR who did not require an insulin infusion in order to minimize metabolic derangements. Because the FDR were insulin resistant, pre-clamp insulin concentrations were also higher than in the control subjects. Increments for most signalling parameters were, however, almost comparable to the control group and all significant. Nevertheless, glucose disposal was significantly reduced compared to the control subjects. Taken together, our data in the FDR and the diabetic patients therefore suggest that the genetic background for diabetes and the disease itself, as long as its metabolic derangements are compensated, are not associated with detectable alterations at the investigated signalling steps. Our data in FDR are quite consistent with those by investigators [5], who also did not observe differences in signalling between FDR and control subjects at the clamp insulin concentration. The higher pre-clamp signalling levels in the FDR in their study compared to our study is most probably explained by the fact that they recruited FDR with impaired glucose tolerance, whereas we recruited FDR with normal glucose tolerance. In contrast, Pratipanawatr et al. [4] described reduced PI3'kinase signalling in FDR at the clamp insulin concen- 
tration a discrepancy which could be because biopsies were obtained already $30 \mathrm{~min}$ after the start of the clamp insulin infusion whereas glucose disposal was measured between the 90th and 120th min. At the 30th min, a steady-state between arterial and interstitial insulin [40] and steady-state glucose disposal (Fig. 1C) has not been reached, and also signalling intensities like insulin receptor kinase and PI3'-kinase activity have not reached their final levels (Fig. 3, [41, 43]). Other potential reasons include different ethnicity (Mexican-American) and lower BMI of the subjects in their study.

It has previously been proposed that an altered abundance of signalling proteins could contribute to the insulin resistance in Type II diabetes, and low IRS-1 gene and protein expression in human adipocytes have been reported to predict insulin resistance and Type II diabetes [50]. In our study, we did not detect diabetes-associated alterations in the abundance of IR, IRS-1, p85, or Akt in skeletal muscle, suggesting that no such alterations exist in this tissue, at least not following normalization of hyperglycaemia and NEFA concentrations.

Glycogen synthesis represents a major pathway of glucose disposal in skeletal muscle after insulin stimulation [7]. Glycogen synthase is stimulated by insulin, and there are several indications that PI3'-kinase activity and potentially also Akt activation is necessary for this activation $[51,52]$. In this study, we did not detect a reduced activity at the clamp insulin concentration in the diabetic patients and FDR subjects. This would be consistent with the notion that the alteration that lead to the reduced glucose disposal in these subjects did not involve the signalling towards this enzyme. This could not be in contrast to a previous study where a reduced glycogen synthase activity has been found in Type II diabetic subjects [53] because the normalisation of glucose and NEFA concentrations in the present study could have reversed potential alterations in glycogen synthase activity. Moreover it needs to be taken into consideration that the reported alterations in Type II diabetes have been subtle. Thus, significant differences have often only been found between obese Type II diabetic subjects and lean, but not obese, control subjects $[23,38]$. We can therefore not exclude that a potential difference in glycogen synthase activity in the diabetic patients was missed due to the lower number of subjects. This is also true for the FDR subjects, where we observed similar activities as in the controls at the clamp insulin concentration.

Taken together, the question, whether insulin signalling at the level of PI3'-kinase and/or Akt is impaired in Type II diabetes remains controversial. Our results obtained following normalization of glucose and NEFA concentrations patients suggest that at least no major alterations exist under these conditions. This is also confirmed by our data in the FDR subjects who, despite an increased risk for the development of Type II diabetes, displayed no detectable abnormalities. In the context of other studies, where such alterations were partly found, this could indicate that secondary factors like hyperglycaemia [26], increased NEFA concentrations [27] or obesity [23, 54] interfere with PI3'-kinase/Akt signalling in overt diabetes. With the present methodology, it cannot be excluded that despite similar overall activity/phosphorylation of the investigated signalling molecules an altered spatial organisation contributed to an altered signalling in FDR and diabetic subjects. Moreover, it cannot be excluded that subtle, maybe genetic, abnormalities exist at the level of PI3'-kinase and/or Akt signalling that were not detected in our study due to the variation of the results and the number of subjects studied. Such subtle alterations or sustained increased basal signalling levels in diabetic patients or patients at risk for the development of diabetes could contribute to the development of alterations in the signalling downstream of PI3'-kinase and/or Akt that we propose in the present paper. For example, could sustained increases of signalling at the level of PI3'-kinase and/or Akt result in a desensitisation of downstream signalling elements or final effector system responsible for glucose uptake. There is indeed some previous evidence that such a desensitisation might occur. Thus in healthy subjects glucose disposal in euglycaemic hyperinsulinaemic clamps has been reported to be lower if moderate euglycaemic hyperinsulinaemia (120 pmol/l) had been induced for $72 \mathrm{~h}$ before these clamps [55].

In summary, our data provide evidence that the decreased glucose disposal in Type II diabetic patients and FDR is associated with alterations downstream or independent of PI3'-kinase activation and/or $\mathrm{Thr}^{308}$ Akt-phosphorylation. In addition, our results suggest that in subjects with the genetic background of Type II diabetes or Type II diabetic patients with normalized glucose and NEFA concentrations, signalling towards PI3'-kinase and Akt is not substantially altered. The potential role of sustained increased basal insulin and insulin signalling levels in diabetic patients and FDR for the development of impaired signalling downstream of $\mathrm{PKB} / \mathrm{Akt}$ remains to be determined.

Acknowledgements. We gratefully acknowledge the superb technical assistance of A. Eirich. This work was supported in part by grants from the Deutsche Forschungsgemeinschaft (KL 503/7-3 to H.H. Klein), the German Diabetes Association (H.H. Klein), the Danish Diabetes Association (K. Levin, H. Beck-Nielsen), the Novo Nordisk Foundation (K. Levin), and the Institute of Clinical Research, Odense University Hospital (H. Beck-Nielsen). 


\section{References}

1. DeFronzo RA (1988) Lilly lecture 1987. The triumvirate: beta-cell, muscle, liver. A collusion responsible for NIDDM. Diabetes 37:667-687

2. Eriksson J, Franssila-Kallunki A, Ekstrand A et al. (1989) Early metabolic defects in persons at increased risk for non-insulin-dependent diabetes mellitius. N Engl J Med 321:337-343

3. Groop L, Forsblom C, Lehtovirta M (1997) Characterization of the prediabetic state. Am J Hypertens 10:172S-180S

4. Pratipanawatr W, Pratipanawatr T, Cusi K et al. (2001) Skeletal muscle insulin resistance in normoglycemic subjects with a strong family history of type 2 diabetes is associated with decreased insulin-stimulated insulin receptor substrate-1 tyrosine phosphorylation. Diabetes 50:25722578

5. Storgaard H, Song XM, Jensen CB et al. (2001) Insulin signal transduction in skeletal muscle from glucose-intolerant relatives with type 2 diabetes. Diabetes 50:2770-2778

6. Martin BC, Warram JH, Krolewski AS, Bergman RN, Soeldner JS, Kahn CR (1992) Role of glucose and insulin resistance in development of type 2 diabetes mellitus: results of a 25-year follow-up study. Lancet 340:925-929

7. Beck-Nielsen H, Groop LC (1994) Metabolic and genetic characterization of prediabetic states. Sequence of events leading to non-insulin-dependent diabetes mellitus. J Clin Invest 94:1714-1721

8. Yki-Jarvinen H (1992) Glucose toxicity. Endocr Rev $13: 415-431$

9. Boden G (1997) Role of fatty acids in the pathogenesis of insulin resistance and NIDDM. Diabetes 46:3-10

10. Zierath JR, Ryder JW, Doebber T et al. (1998) Role of skeletal muscle in thiazolidinedione insulin sensitizer (PPAR $\gamma$ agonist) action. Endocrinology 139:5034-5041

11. Virkamäki A, Ueki K, Kahn CR (1999) Protein-protein interaction in insulin signalling and the molecular mechanism of insulin resistance. J Clin Invest 103:931-943

12. Krook A, Björnholm M, Galuska D et al. (2000) Characterization of signal transduction and glucose transport in skeletal muscle from type 2 diabetic patients. Diabetes 49 : 284-292

13. Zierath JR, Krook A, Wallberg-Henriksson H (2000) Insulin action and insulin resistance in human skeletal muscle. Diabetologia 43:821-835

14. Coffer PJ, Jin J, Woodgett JR (1998) Protein kinase B (c-Akt): A multifunctional mediator of phosphatidylinositol 3-kinase activation. Biochem J 335:1-13

15. Jiang T, Sweeney G, Rudolf MT, Klip A, Traynor-Kaplan A, Tsien RY (1998) Membrane-permeant esters of phosphatidylinositol 3,4,5-triphosphate. J Biol Chem 273: 11017-11024

16. Krook A, Whitehead JP, Dobson SP et al. (1997) Two naturally occurring insulin receptor tyrosine kinase domain mutants provide evidence that phosphoinositide 3-kinase activation alone is not sufficient for the mediation of insulin's metabolic and mitogenic effects. J Biol Chem 272:3020830214

17. Pessin JE, Saltiel AR (2000) Signalling pathways in insulin action: Molecular targets of insulin resistance. J Clin Invest 106:165-169

18. Klein HH, Vestergaard H, Kotzke G, Pedersen O (1995) Elevation of serum insulin concentration during euglycaemic hyperinsulinemic clamp studies leads to similar activation of insulin receptor kinase in skeletal muscle of subjects with and without NIDDM. Diabetes 44:1310 1317
19. Arner P, Pollare T, Lithell H, Livingston JN (1987) Defective insulin receptor tyrosine kinase in human skeletal muscle in obesity and Type II (non-insulin dependent) diabetes mellitus. Diabetologia 30:437-440

20. Maegawa H, Shigeta Y, Egawa K, Kobayashi M (1991) Impaired autophosphorylation of insulin receptors from abdominal skeletal muscles in nonobese subjects with NIDDM. Diabetes 40:815-819

21. Björnholm M, Kawano Y, Lehtihet M, Zierath JR (1997) Insulin receptor substrate-1 phosphorylation and phosphatidylinositol 3-kinase activity in skeletal muscle from NIDDM subjects after in vivo insulin stimulation. Diabetes 46:524-527

22. Kim YB, Nikoulina SE, Ciaraldi TP, Henry RR, Kahn BB (1999) Normal insulin-dependent activation of Akt/protein kinase $\mathrm{B}$, with diminished activation of phosphoinositide 3-kinase, in muscle in type 2 diabetes. J Clin Invest 104:733-741

23. Cusi K, Maezono K, Osman A et al. (2000) Insulin resistance differentially affects the PI 3-kinase- and MAP kinase-mediated signalling in human muscle. J Clin Invest 105:311-20

24. Krook A, Roth RA, Jiang XJ, Zierath JR, WallbergHenriksson H (1998) Insulin-Stimulated Akt Kinase Activity Is Reduced in Skeletal Muscle From NIDDM Subjects. Diabetes 47:1281-1286

25. Kim YB, Zhu JS, Zierath JR, Shen HQ, Baron AD, Kahn BB (1999) Glucosamine infusion in rats rapidly impairs insulin stimulation of phosphoinositide 3-kinase but does not alter activation of Akt/protein kinase B in skeletal muscle. Diabetes 48:310-320

26. Kurowski TG, Lin Y, Luo Z et al. (1999) Hyperglycaemia inhibits insulin activation of Akt/protein kinase B but not phosphatidylinositol 3-kinase in rat skeletal muscle. Diabetes 48:658-663

27. Dresner A, Laurent D, Marcucci M et al. (1999) Effects of free fatty acids on glucose transport and IRS-1 associated phosphatidylinositol 3-kinase activity. J Clin Invest 103: 253-259

28. McGuire EA, Helderman JH, Tobin JD, Andres R, Berman M (1976) Effects of arterial versus venous sampling on analysis of glucose kinetics in man. J Appl Physiol 41:565-573

29. Hother-Nielsen O, Henriksen JE, Staehr P, Beck-Nielsen H (1995) Labelled glucose infusate technique in clamp studies. Is precise matching of glucose specific activity important? Endocrinol Metab 2:275-287

30. Steele R (1959) Influence of glucose loading and of injected insulin on hepatic glucose output. Ann NY Acad Sci 82:420-430

31. Toivonen E, Hemmila I, Marniemi J, Jorgensen PN, Zeuthen J, Lovgren T (1986) Two-site time-resolved immunofluorometric assay of human insulin. Clin Chem 32:637-640

32. Bergstrom J (1975) Percutaneous needle biopsy of skeletal muscle in physiological and clinical research. Scand J Clin Lab Invest 35:609-616

33. Klein HH, Kowalewski B, Drenckhan M, Neugebauer S, Matthaei S, Kotzke G (1993) A microtiter well assay system to measure insulin activation of insulin receptor kinase in intact human mononuclear cells. Diabetes 42:883890

34. Klein HH, Muller R, Drenckhan M, Schutt M, Batge B, Fehm HL (2000) Insulin activation of insulin receptor kinase in erythrocytes is not altered in non-insulin-dependent diabetes and not influenced by hyperglycaemia. J Endocrinol 166:275-281 
35. Krützfeldt J, Grünweller A, Raasch W, Drenckhan M, Klein H (1999) Microtiter well assays for protein tyrosine phosphatase activities directed against phosphorylated insulin receptor or insulin receptor substrate-1. Anal Biochem 271:97-99

36. Krützfeldt J, Kausch C, Volk A et al. (2000) Insulin signalling and action in cultured skeletal muscle cells from lean healthy humans with high and low insulin sensitivity. Diabetes 49:992-998

37. Mandarino LJ, Wright KS, Verity LS et al. (1987) Effects of insulin infusion on human skeletal muscle pyruvate dehydrogenase, phosphofructokinase, and glycogen synthase. Evidence for their role in oxidative and nonoxidative glucose metabolism. J Clin Invest 80:655-663

38. Damsbo P, Vaag A, Hother-Nielsen O, Beck-Nielsen H (1991) Reduced glycogen synthase activity in skeletal muscle from obese patients with and without Type II (non-insulin-dependent) diabetes mellitus. Diabetologia 34:239-245

39. Baumann CA, Ribon V, Kanzaki M et al. (2000) CAP defines a second signalling pathway required for insulin-stimulated glucose transport. Nature 407:202-207

40. Castillo C, Bogardus C, Bergman RN, Thuillez P, Lillioja S (1994) Interstitial insulin concentrations determine glucose uptake rates but not insulin resistance in lean and obese men. J Clin Invest 93:10-16

41. Wojtaszewski JFP, Hansen BF, Kiens B, Richter EA (1997) Insulin signalling in human skeletal muscle-Time course and effect of exercise. Diabetes 46:1775-1781

42. Wojtaszewski JFP, Hansen BF, Gade J et al. (2000) Insulin signalling and insulin sensitivity after exercise in human skeletal muscle. Diabetes 49:325-331

43. Grimmsmann T, Levin K, Meyer MM, Beck-Nielsen H, Klein HH (2002) Delays in insulin signalling towards glucose disposal in human skeletal muscle. J Endocrinol 172:645-651

44. Freidenberg G, Suter S, Henry RR, Reichart D, Olefsky JM (1991) In vivo stimulation of the insulin receptor kinase in human skeletal muscle. Correlation with insulin-stimulated glucose disposal during euglycaemic clamp studies. J Clin Invest 87:2222-2229

45. Yenush L, Makati KJ, Smith-Hall J, Ishibashi O, Myers MG Jr, White MF (1996) The Pleckstrin Homology Domain Is the Principle Link between the Insulin Receptor and IRS-1. J Biol Chem 271:24300-24306
46. Nolan JJ, Freidenberg G, Henry RR, Reichart D, Olefsky JM (1994) Role of human skeletal muscle insulin receptor kinase in the in vivo insulin resistance of noninsulindependent diabetes mellitus and obesity. J Clin Endocrinol Metab 78:471-477

47. Eldar-Finkelman H, Krebs EG (1997) Phosphorylation of insulin receptor substrate 1 by glycogen synthase kinase 3 impairs insulin action. Proc Natl Acad Sci USA 94:96609664

48. Jansson PAE, Fowelin JP, von Schenck HP, Smith UP, Lönnroth PN (1993) Measurement by microdialysis of the insulin concentration in subcutaneous interstitial fluid. Diabetes 42:1469-1473

49. Baron AD (1994) Hemodynamic actions of insulin. Am J Physiol 267:E187-E202

50. Carvalho E, Jansson PAE, Axelsen M et al. (1999) Low cellular IRS-1 gene and protein expression predict insulin resistance and NIDDM. FASEB J 13:2173-2178

51. Shepherd PR, Nave BT, Siddle K (1995) Insulin stimulation of glycogen synthesis and glycogen synthase activity is blocked by wortmannin and rapamycin in 3T3-L1 adipocytes: evidence for the involvement of phosphoinositide 3-kinase and p70 ribosomal protein-S6 kinase. Biochem $\mathbf{J}$ 305:25-28

52. van Weeren PC, de Bruyn KM, de Vries-Smits AM, van Lint J, Burgering BM (1998) Essential role for protein kinase $\mathrm{B}(\mathrm{PKB})$ in insulin -induced glycogen synthase kinase 3 inactivation. Characterization of dominant-negative mutant of PKB. J Biol Chem 273:13150-13156

53. Thorburn AW, Gumbiner B, Bulacan F, Brechtel G, Henry RR (1991) Multiple defects in muscle glycogen synthase activity contribute to reduced glycogen synthesis in noninsulin dependent diabetes mellitus. J Clin Invest 87:489495

54. Goodyear LJ, Giorgino F, Sherman LA, Carey J, Smith RJ, Dohm GL (1995) Insulin receptor phosphorylation, insulin receptor substrate-1 phosphorylation, and phosphatidylinositol 3-kinase activity are decreased in intact skeletal muscle strips from obese subjects. J Clin Invest 95:21952204

55. Del Prato S, Leonetti F, Simonson DC, Sheehan P, Matsuda M, DeFronzo RA (1994) Effect of sustained physiologic hyperinsulinaemia and hyperglycaemia on insulin secretion and insulin sensitivity in man. Diabetologia 37:1025-1035 